Special issue in honor of Prof. H.K. Lichtenthaler

\title{
Drought tolerance monitoring of apple rootstock M.9-T337 based on infrared and fluorescence imaging
}

\author{
D.T. GAO ${ }^{*, * *, * * *}$, C.Y. SHI ${ }^{* * *}$, Q.L. LI ${ }^{* * *}$, Z.F. WEI ${ }^{* * *}$, L. LIU $^{* * *}$, and J.R. FENG ${ }^{*, * *,+}$ \\ Department of Horticulture, College of Agriculture, Shihezi University, 832003 Shihezi, Xinjiang, China* \\ Xinjiang Production and Construction Corps Key Laboratory of Special Fruits and Vegetables, Cultivation \\ Physiology and Germplasm Resources Utilization, 832003 Shihezi, Xinjiang, China ${ }^{* *}$ \\ Zhengzhou Fruit Research Institute, Chinese Academy of Agricultural Sciences, 450009 Zhengzhou, Henan, \\ China ${ }^{* * *}$
}

\begin{abstract}
Apple rootstock seedling M.9-T337 was selected to explore the effect of drought stress. The findings indicated that the relative water content of both the leaf and soil gradually decreased with an increase in drought stress. The water-use efficiency of the leaves increased gradually but decreased sharply after $20 \mathrm{~d}$ of drought. Changes in the gas-exchange parameters and chlorophyll fluorescence parameters reflected the gradual decrease in the photosynthetic capacity of the plants with drought stress duration. Infrared thermal imaging showed significant temperature differences between the drought-stressed and control plants after $15 \mathrm{~d}$ of drought treatment. When irreversible damage occurred under drought stress, the crop water-stress index and relative water content of the leaf and soil were $0.7,60.5$, and $17.8 \%$, respectively. Based on the results, we formulated a drought stress-grade standard. Further, we established that the best time for irrigation is when drought stress reaches grade 3 .
\end{abstract}

Keywords: chlorophyll fluorescence; drought stress; infrared thermal imaging; M.9-T337; photosynthesis.

\section{Introduction}

Drought is an important factor that restricts the growth and development of apple (Malus domestica Borkh.) plants. Apples, one of the largest fruit-bearing species in the world in terms of yield and cultivation, are predominantly produced in arid and semiarid regions. As apples are usually propagated by grafting, the drought resistance of the rootstocks is vital to the plants' growth (Jensen et al. 2012). High-density planting systems have been widely accepted in the apple industry as effective tools to increase orchard efficiency (Weber 2001, Srivastava et al. 2019). The apple dwarfing rootstock is primarily derived from the M-line dwarfing rootstock, T337, which belongs to the

\section{Highlights}

- Infrared thermal imaging was first applied to apple drought detection

- A drought stress-grade standard was established in detail

- The optimum watering time and critical index of irreversible damage were identified
Received 31 December 2020

Accepted 24 June 2021

Published online 23 July 2021

${ }^{+}$Corresponding author phone: +86-371-65330959, fax: +86-371-65330987

e-mail: fengjr102@gmail.com

Abbreviations: $C_{\mathrm{i}}$ - intercellular $\mathrm{CO}_{2}$ concentration; CWSI - crop water stress index; $E$ - transpiration rate; $\mathrm{F}_{\mathrm{v}} / \mathrm{F}_{\mathrm{m}}-$ maximal quantum yield of PSII photochemistry; $g_{\mathrm{s}}$ - stomatal conductance; NPQ - nonphotochemical quenching; $P_{\mathrm{N}}$ - net photosynthetic rate; $\mathrm{q}_{\mathrm{P}}-$ photochemical quenching coefficient; RWC - relative water content; WUE - water-use efficiency; $\mathrm{Y}_{(\mathrm{II})}$ - actual photochemical efficiency of PSII.

Acknowledgments: This work was supported by the featured forest fruit industry simplified and standardized cultivation model research and demonstration promotion (2019AA004), science and technology research project in Henan province (212102110428), and basic research funds of Zhengzhou Fruit Research Institute, Chinese Academy of Agricultural Sciences (0212122).

Conflict of interest: The authors declare that they have no conflict of interest. 
superior line M.9. Line M.9-T337 is the most successful and widely used rootstock due to its characteristics of early fruiting, strong adaptability, and high yield (Höhnle and Weber 2010, Gao et al. 2012). Therefore, studying the drought resistance of M.9-T337 is of great significance to the development of the apple industry.

Drought not only inflicts a morphological effect on apple plants but also on the physiological and biochemical reactions that take place within the plant (Bartels and Sunkar 2005). When plants are subjected to drought stress, the leaves - the most sensitive organs of the plant manifest by wilting and drooping, and the normal growth of branches and roots is also inhibited (Hao et al. 2015, Shao et al. 2016). Photosynthesis is the most basic physiological process of plants. The photosynthetic activity of plants can be reflected by indicators, such as net photosynthetic rate $\left(P_{\mathrm{N}}\right)$, stomatal conductance $\left(g_{\mathrm{s}}\right)$, intercellular carbon dioxide $\left(\mathrm{CO}_{2}\right)$ concentration $\left(C_{\mathrm{i}}\right)$, transpiration rate $(E)$, and water-use efficiency (WUE). Drought stress will reduce the photosynthetic capacity of apple leaves and can cause plant senescence. The response of photosynthesis to drought stress mainly includes two factors: the stomatal factor and the nonstomatal factor. The former occurs owing to stomatal closure caused by drought stress, which blocks the entry of $\mathrm{CO}_{2}$ into leaves (Siddique et al. 2000, Silva et al. 2007, Jaleel et al. 2009, Anjum et al. 2011, Basu et al. 2016). In contrast, the latter is caused by damage to photosynthetic organs accompanied by a decrease in photosynthetic pigment content, PSII activity, and photosynthetic enzyme activity (van Rensburg and Krüger 1993, Escalona et al. 1999, Earl 2002).

Drought stress can directly or indirectly affect the photosynthetic performance of leaves, and PSII plays an important role in plant responses to environmental stress (Miyashita et al. 2005, Liu et al. 2010). The active center of PSII is crucial to the absorption, transmission, and conversion of light energy (Jiang et al. 2008). As an essential indicator of photosynthetic function, chlorophyll fluorescence not only reflects the activity of PSII accurately but is also an ideal probe for studying the relationship between plant photosynthetic physiology and adversity stress (Maxwell and Johnson 2000, Woo et al. 2008). By observing changes in chlorophyll fluorescence parameters, it is possible to analyze the general pattern of light energy utilization in plants and its dynamic response under the influence of varying external factors (Farage et al. 2006, Hogewoning and Harbinson 2007, Baker 2008). When plants are under drought stress, the maximum photochemical efficiency $\left(\mathrm{F}_{\mathrm{v}} / \mathrm{F}_{\mathrm{m}}\right)$ of leaves is a simple and fast way to reflect the degree of stress (Henriques 2009, Zai et al. 2012). Nonphotochemical fluorescence quenching (NPQ) expresses the ability of plants to dissipate excess light energy into heat, whereas photochemical fluorescence quenching $\left(\mathrm{q}_{\mathrm{P}}\right)$ represents fluorescence quenching caused by photosynthesis and indicates the level of photosynthetic activity (Baker 2008).

Among all monitored indicators of plant stress, the surface temperature of the plant is considered to respond fastest to stress, before the appearance of visual symptoms
(Khanal et al. 2017). Infrared thermal imaging technology is an emerging technology developed in recent years that can detect the real-time temperature of plant leaves conveniently. The aggravation of drought stress has been shown to increase the temperature of leaves (Siddique et al. 2000, Baker et al. 2007, Liu et al. 2011). Leinonen et al. (2006) used thermal imaging to obtain canopy temperatures and estimate the $g_{s}$ of grapevines under drought stress. Lima et al. (2016) used thermal imaging technology to study the relationship between water stress and three physiological indexes $\left(g_{\mathrm{s}}, E\right.$, and $\left.P_{\mathrm{N}}\right)$. Infrared thermal imaging technology has also been used to monitor the drought stress of maize and screen drought-resistant varieties (Zia et al. 2013). In addition to detecting water stress, infrared thermal imaging technology is widely used in the detection of a range of stresses, including diseases, freezing, and damage (Jones 2004, Vadivambal and Jayas 2011, Ring and Ammer 2012, Wang et al. 2013). Infrared thermal imaging technology is primarily applied to field crops and has been applied less to fruit trees. With apples, it is used to detect fruit disease or damage (Varith et al. 2003, Baranowski et al. 2008, 2009; Baranowski and Mazurek 2009); however, this study is the first to apply this technology to drought stress research.

In this study, the morphological changes of plants, relative water contents (RWC) of the leaves and soil, gasexchange parameters, chlorophyll fluorescence parameters, and the leaf temperature were measured to describe the state changes of the apple rootstock M.9-T337 under drought stress. M.9-T337 is a new dwarf rootstock with excellent production performance. To support its better utilization in the future, post-drought rehydration experiments were conducted to establish the critical indicators of when drought stress produces irreversible damage. Moreover, the formation of drought stress-grade standards was attempted to provide theoretical support for the drought-resistant cultivation of apples, thereby providing references for precision irrigation in the apple industry in the future.

\section{Materials and methods}

Plants and experimental design: The experiments were conducted under natural light in the glasshouse of the Zhengzhou Fruit Research Institute, Chinese Academy

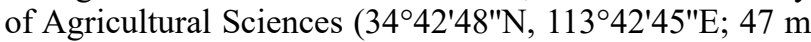
above sea level), Zhengzhou, Henan, China. The temperature and humidity in the glasshouse were approximately $28^{\circ} \mathrm{C}$ and $70 \%$, respectively. Two-month-old tissuecultured apple saplings of M.9-T337 (MS medium, 16/8-h light/dark cycle, $22 \pm 1^{\circ} \mathrm{C}$ ) were selected and transplanted into pots (diameter of $17 \mathrm{~cm}$, height of $14 \mathrm{~cm}$ ) containing homogenous soil (vermiculite, perlite, and peat soil; volume ratio $=1: 1: 3$ ) with one plant per pot and cultivated for two months before the drought stress experiments began. In the afternoon preceding the initiation of the experiment, the plants were fully irrigated and excess water was allowed to drain overnight. After draining, the pots were weighed to a precision of $1 \mathrm{~g}$ using a digital balance (MT201, Meilen, Shenzhen, China) to determine 
the mass at pot water capacity (Pot mass initial $_{\text {). The pot }}$ mass was measured every day after the experimental drought stress commenced (Pot mass $_{\text {daily }}$ ). According to the effect of drought stress on plant state, we selected 15 , 20 , and $25 \mathrm{~d}$ after drought treatment for rehydration, and observed the recovery degree and survival status of plants by measuring the RWC of leaves and soil, gas-exchange parameters, leaf temperature, and chlorophyll fluorescence parameters. After $3 \mathrm{~d}$ of rehydration, the state of the plants was recorded. At the end of the experiment, the plants were removed from each pot and each plants' respective soil was oven-dried at $105^{\circ} \mathrm{C}$ for $48 \mathrm{~h}$ to determine the dry mass (Soil DM). Then, the soil water content, expressed as the water fraction $\left[\mathrm{g} \mathrm{g}^{-1}\right]$, was determined as $\mathrm{SWC}=(\mathrm{Pot}$ mass $_{\text {daily }}$ - Soil DM $) /($ Pot mass initial - Soil DM) (Centritto et al. 2011).

Leaf RWC assays: Leaf RWC was measured using the method described by Liao et al. (2018). Counting down from the apex, the fifth to eighth mature leaves of similar sizes were selected and the fresh mass (FM) was measured using an electronic balance (E5500S, Sartorius, Göttingen, Germany). The turgid mass (TM) was recorded after rehydrating the samples in vials containing water to allow full saturation in darkness for $24 \mathrm{~h}$. The dry mass (DM) was measured after drying at $80^{\circ} \mathrm{C}$ for $24 \mathrm{~h}$. RWC was calculated using the following equation: $\mathrm{RWC}[\%]=$ $(\mathrm{FM}-\mathrm{DM}) /(\mathrm{TM}-\mathrm{DM}) \times 100$.

The gas-exchange parameters were monitored using a portable photosynthesis system (CIRAS-3, PP Systems, MA, USA). $P_{\mathrm{N}}, E, g_{\mathrm{s}}, C_{\mathrm{i}}$, and WUE were measured using the sixth fully expanded leaf (from the apex) between 9:00 and 11:00 $\mathrm{h}$ on sunny days at different treatment stages. The average leaf temperature was $26^{\circ} \mathrm{C}$, the $\mathrm{CO}_{2}$ concentration was $380 \pm 10 \mu \mathrm{mol} \mathrm{mol}^{-1}$, and the relative humidity and light intensity were adjusted to $60 \%$ and $600 \mu \mathrm{mol}($ photon $) \mathrm{m}^{-2} \mathrm{~s}^{-1}$, respectively.

The chlorophyll fluorescence parameters of PSII were determined using pulse amplitude modulation fluorimetry (IMAGING-PAM, Walz GmbH, Effeltrich, Germany). A detailed description of this instrument is provided by Schreiber et al. (2007). After $20 \mathrm{~min}$ of dark adaptation of the leaves, the intrinsic fluorescence $\left(\mathrm{F}_{0}\right)$ of the antenna system of fully oxidized PSII was measured according to the instrument directions. Then, a saturating flash was applied to detect the maximal fluorescence $\left(\mathrm{F}_{\mathrm{m}}\right)$ of fully reduced PSII reaction centers (Figueroa et al. 2003). The variable fluorescence $F_{v}$ was obtained as the difference between $\mathrm{F}_{\mathrm{m}}$ and $\mathrm{F}_{0}$, together with $\mathrm{F}_{\mathrm{v}} / \mathrm{F}_{\mathrm{m}}$ (Schreiber et al. 1986). The effective PSII quantum yield [Y $\left.\mathrm{Y}_{(\mathrm{II})}\right]$ was calculated according to the formula: $\mathrm{Y}_{(\mathrm{II})}=\left(\mathrm{F}_{\mathrm{m}}{ }^{\prime}-\mathrm{F}\right) / \mathrm{F}_{\mathrm{m}}{ }^{\prime}$ (Genty et al. 1989), q $\mathrm{q}_{\mathrm{P}}$ was calculated according to Schreiber et al. (1986): $\mathrm{q}_{\mathrm{P}}=\left(\mathrm{F}_{\mathrm{m}}{ }^{\prime}-\mathrm{F}\right) /\left(\mathrm{F}_{\mathrm{m}}{ }^{\prime}-\mathrm{F}_{0}{ }^{\prime}\right)$, with $\mathrm{F}_{0}{ }^{\prime}$ (minimal fluorescence) being estimated by the equation $\mathrm{F}_{0}^{\prime}=\mathrm{F}_{0} /\left(\mathrm{F}_{\mathrm{v}} / \mathrm{F}_{\mathrm{m}}+\mathrm{F}_{0} / \mathrm{F}_{\mathrm{m}}{ }^{\prime}\right)$ (Oxborough and Baker 1997). NPQ was calculated according to Bilger and Björkman (1990): NPQ $=\left(F_{m}-F_{m}{ }^{\prime}\right) / F_{m}$. When the disks were illuminated, the maximum fluorescence yield $\left(\mathrm{F}_{\mathrm{m}}{ }^{\prime}\right)$ was detected, which was normally lower than $\mathrm{F}_{\mathrm{m}}$ owing to nonphotochemical quenching (i.e., heat dissipation). All parameters were read directly in the report window of a computer connected to IMAGING-PAM.

Thermal imaging: Average surface temperatures of all plants across the different stages of drought stress were measured using a FLIR T600 (FLIR Systems, Stockholm, Sweden) thermal camera $(7.5-14 \mu \mathrm{m})$ and recorded as a time series (day 1, 5, 10, 15, 20, and 25) using FLIR Tool software (version 6.4.18039.1003). A temperaturebased crop water-stress index (CWSI) was developed by Idso et al. (1981). The CWSI is defined as CWSI = $\left(T_{1}-T_{w}\right) /\left(T_{d}-T_{w}\right)$, where $T_{1}$ is the leaf temperature, $T_{w}$ is the canopy temperature of the control plants corresponding to a well-watered leaf with the stomata fully open, and $T_{d}$ is the canopy temperature, which equates to the temperature of a nontranspiring leaf, i.e., one with stomata completely closed. Higher values of the CWSI represent higher stress. The theoretical maximum of CWSI is 1.0 if $\mathrm{T}_{1}=\mathrm{T}_{\mathrm{d}}$, which indicates complete stomatal closure.

Physiological analysis of roots: The fresh mass, length, surface, and volume of the total roots from different treatments were measured. The roots were scanned and the morphological parameters were analyzed using the $L A-S$ plant root analyzer system (WSeen, Hangzhou, China).

Statistical analysis: Each measurement was carried out on four to six plants. All data were entered into Excel 2010 and the figures were created using SigmaPlot 14.0. The data were evaluated using Tukey's test $(p<0.05)$ in the analysis of variance (ANOVA) program of SPSS (IBM, SPSS Statistics v. 19.0).

\section{Results}

Effect of drought stress on plant leaves, roots, and SWC: The morphological changes of the leaves were recorded to determine the degree of drought stress increase (Fig. 1A). When the leaves started to change, we selected several typical leaves at 5-d intervals to represent their current state. After $20 \mathrm{~d}$ of drought, the edges of some leaves began turning yellow, and the scorched yellow extended from the edges to the middle of the leaves five days later (Fig. 1A). The RWC gradually decreased with drought treatment until day 20 , followed by a sharp decline during the following days to zero at day 27 (Fig. 1B). When drought stress continued for 15, 20, and $25 \mathrm{~d}$, the RWC of the leaves dropped to an average of $72.9,60.5$, and $31.6 \%$, respectively, and the control was maintained at an average of $90.3 \%$. When the drought treatment began, the soil moisture content decreased gradually; the fastest period of decline occurred between the $10^{\text {th }}$ and $20^{\text {th }}$ day, reaching approximately $30 \%$ on the $15^{\text {th }} \mathrm{d}$ (Fig. 1C). After $30 \mathrm{~d}$ of drought stress, all plants were dead.

Roots of plants from different drought stress periods were selected for scanning analysis (Fig. 1S, supplement). In the control group, the roots were relatively developed 
with fibrous roots and a light brown color. With the intensification of drought, the number of fibrous roots gradually decreased and the color of the roots gradually changed from light brown to black. All root parameters (length, surface area, volume, the number of root tips and bifurcation) increased on the fifth day of drought stress, but only the volume reached a significant level. All parameters gradually decreased with the length of the drought stress period (Table 1S, supplement).

Gas-exchange parameters and WUE in response to drought stress: Gas-exchange parameters and WUE were measured throughout the entire drought stress experiment.
All gas-exchange parameters of the control plants did not change significantly during the entire experimental period as they were cultivated under constant conditions in the greenhouse (Fig. 2). Plants in the treatment group showed a significant response to drought stress. $P_{\mathrm{N}}$ decreased as the degree of drought increased and exhibited a particularly rapid decline after the $20^{\text {th }}$ day (Fig. $2 A$ ). The $g_{\mathrm{s}}$ decreased rapidly at the beginning of the drought process and continued to decrease throughout the rest of the experimental period (Fig. $2 B$ ). The $E$ gradually decreased as the days of drought treatment increased (Fig. $2 C$ ). The $C_{\text {i }}$ gradually decreased until the $20^{\text {th }}$ day and then began to rise rapidly (Fig. $2 D$ ). Differing from these
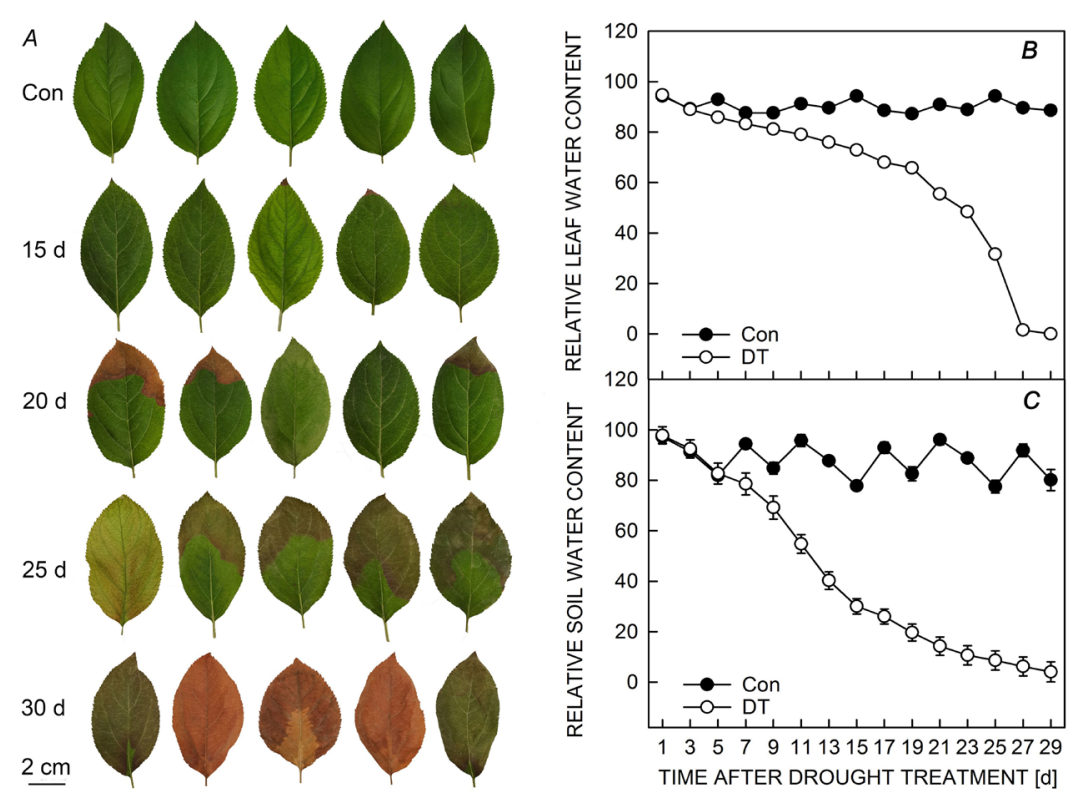

Fig. 1. Changes in leaf state $(A)$, relative leaf water content $(B)$, and relative soil water content $(C)$ with drought continuation. The 'yellowing' starts at the tip of the leaf (between 15 and $20 \mathrm{~d}$ ) and extends to the base of the leaf. Con - control group; DT - drought treatment group. Values are means $\pm \mathrm{SD}, n=6$.

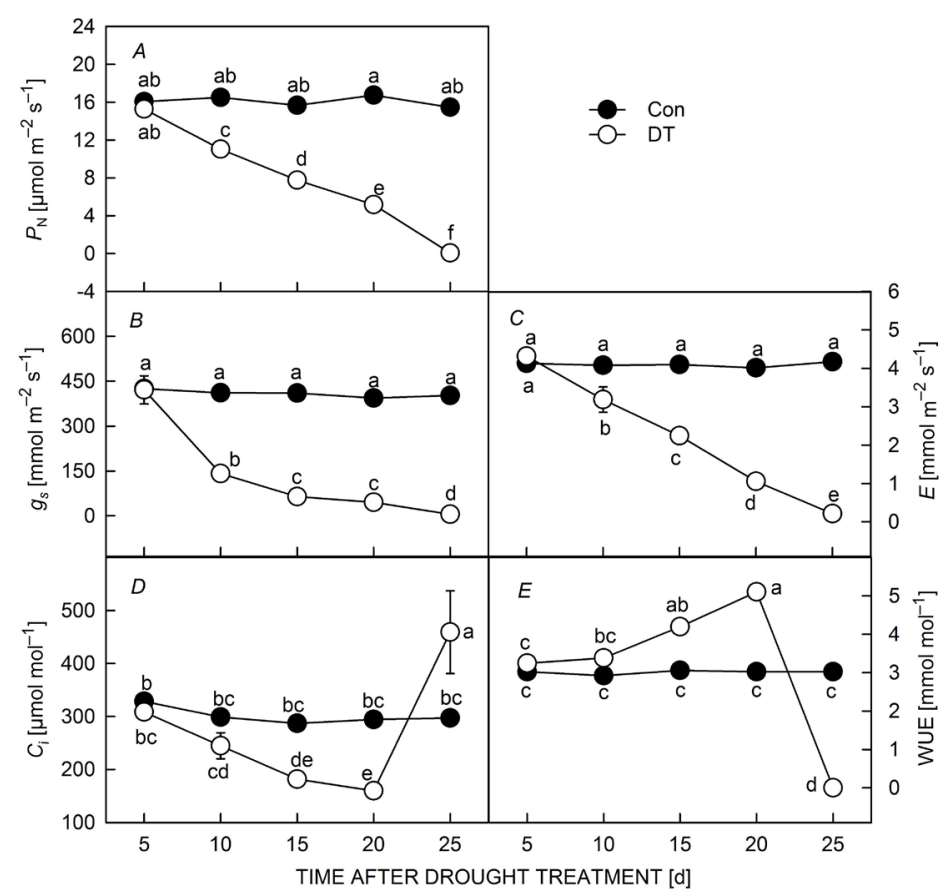

Fig. 2. Changes in gas-exchange parameters and wateruse efficiency of apple plants throughout the duration of drought stress. $P_{\mathrm{N}}-$ net photosynthetic rate; $g_{\mathrm{s}}-$ stomatal conductance; $C_{\mathrm{i}}-$ intercellular $\mathrm{CO}_{2}$ concentration; $E$ - transpiration rate; WUE - water-use efficiency; Con - control group; DT - drought treatment group. Values are means $\pm \mathrm{SD}, n=6$. Different lowercase letters indicate significant differences at $P<0.05$. 
gas-exchange parameters, WUE gradually increased as the days of drought treatment increased but dropped sharply after the $20^{\text {th }}$ day (Fig. $2 E$ ).

Leaf chlorophyll fluorescence: Changes in chlorophyll fluorescence parameters were observed as drought conditions intensified (Fig. 3). The state of the leaves could be observed by the change in leaf color with an elaboration on the process and software described in the "Materials and methods' (Fig. 3A). No significant patterns were observed in $\mathrm{F}_{\mathrm{v}} / \mathrm{F}_{\mathrm{m}}$ before $10 \mathrm{~d}$ of drought treatment. On the $15^{\text {th }}$ day, a difference could be seen in the fluorescence intensity, and the $\mathrm{F}_{\mathrm{v}} / \mathrm{F}_{\mathrm{m}}$ values analysis by Tukey's test also revealed significant differences. $Y_{(I)}$ decreased with drought stress and reached a significant difference on the $10^{\text {th }}$ day; after that, it dropped linearly to zero. NPQ gradually increased as the degree of drought stress increased, and then decreased rapidly after $15 \mathrm{~d}$. When plants were affected by drought stress, the value of $\mathrm{q}_{\mathrm{P}}$ gradually decreased and was observed intuitively through the change in color (Fig. 3).

Effect of drought stress on the temperature of leaves: There was no significant difference in the surface temperature between the control plants and the droughttreated plants from day 0 to day 5 (Fig. 4). On the $10^{\text {th }}$ day, the temperature of the upper leaves began to rise, and the average temperature difference between the control group and the drought stress group was $0.62^{\circ} \mathrm{C}$ and the CWSI was 0.40 . On the $15^{\text {th }}, 20^{\text {th }}$, and $25^{\text {th }} \mathrm{d}$ of drought treatment, the infrared images revealed significant differences between the temperature of the drought-treated plants and that of the control plants, and the CWSI values of drought treated plants were $0.72,0.85$, and 0.92 , respectively.
Recovery state of plants after rehydration: Fig. 5 shows the changes in RWC, WUE, and gas-exchange parameters in the recovery experiment. After rehydration following $15 \mathrm{~d}$ of the drought treatment, all parameters except $g_{\text {s }}$ recovered and exhibited no significant difference compared with those of the control plants. After rehydration following $20 \mathrm{~d}$ of the drought treatment, WUE and $C_{\mathrm{i}}$ recovered but the other parameters did not. None of the parameters recovered to normal levels after rehydration following $25 \mathrm{~d}$ of the drought treatment. Moreover, we measured the temperature differences using infrared thermal imaging (Fig. 2S, supplement) and the chlorophyll fluorescence parameters (Fig. 3S, supplement) after rehydration. After rehydration following $15 \mathrm{~d}$ of the drought treatment, drought had no significant effect on the growth of plants, while the growth recovered to the normal level after rehydration. After rehydration following $20 \mathrm{~d}$ of drought, significant differences in temperature and chlorophyll fluorescence parameters were observed between the control and rehydrated plants, but the plants were still alive. After $25 \mathrm{~d}$ of drought, no matter how much water was applied, the plants did not survive.

Establishment of a drought stress-grade standard for apple plants: According to the phenotypic and physiological changes of the plants throughout the drought stress period, a drought stress-grade standard for apple plants was formulated (Table 1). The drought stress levels, which gradually increase from level 1 to level 6 corresponding to each plant phenotype, are shown in Fig. 6. At drought stress level 1 , there is no significant difference in the external phenotype of the plants; however, the photosynthetic rate decreased, chlorophyll fluorescence index decreased, and leaf temperature significantly increased compared with

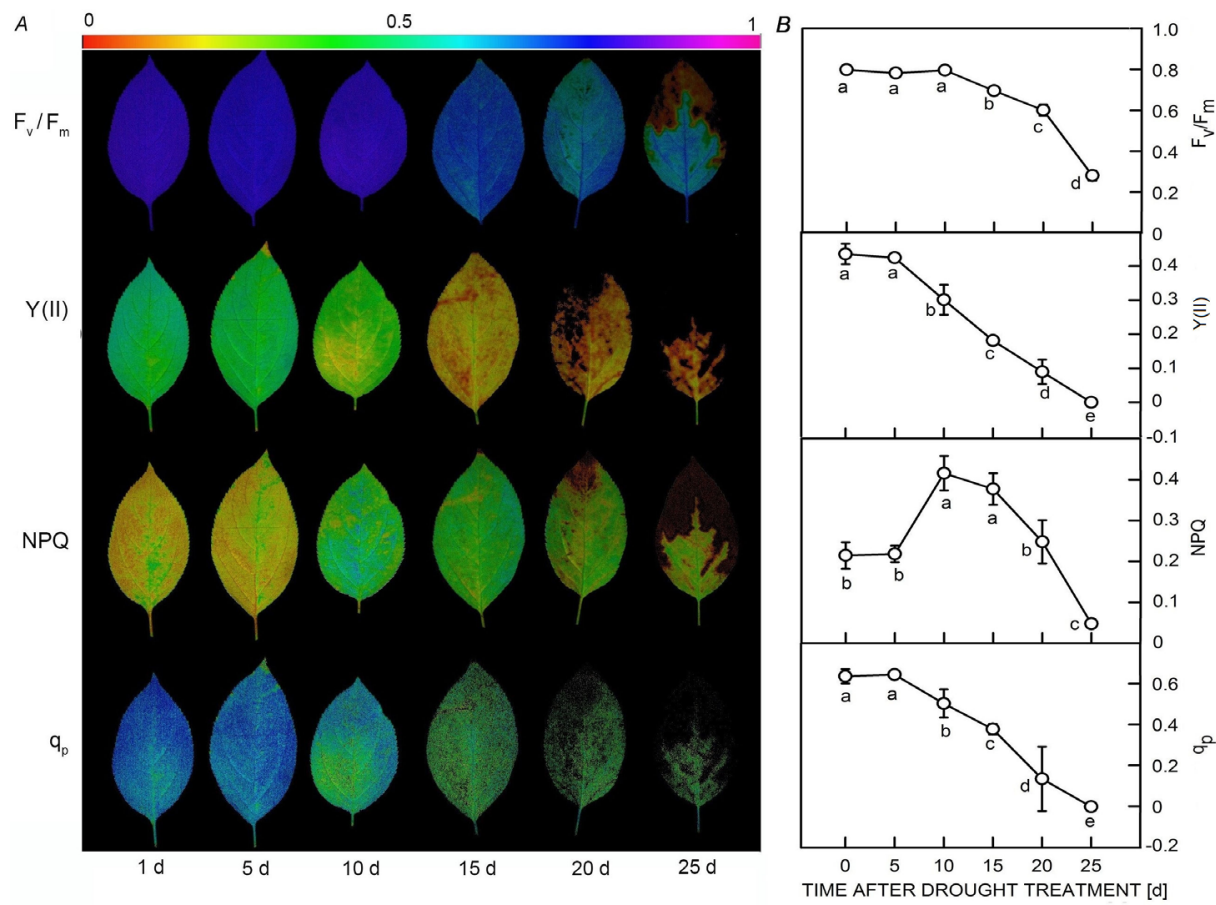

Fig. 3. Changes in chlorophyll fluorescence parameters of apple plants under drought conditions. (A) Chlorophyll fluorescence status of plant leaves in different drought periods $(1,5$, $10,15,20,25$ d). (B) Changes in chlorophyll fluorescence parameter values across drought period. $\quad F_{\mathrm{v}} / \mathrm{F}_{\mathrm{m}}-$ maximum photochemical efficiency; $Y_{(I I)}-$ actual photochemical quantum yield; NPQ - nonphotochemical fluorescence quenching; $\mathrm{q}_{\mathrm{P}}-$ photochemical quenching coefficient. Values are means $\pm \mathrm{SD}$, $n=6$. Different lowercase letters indicate significant differences at $P<0.05$. 


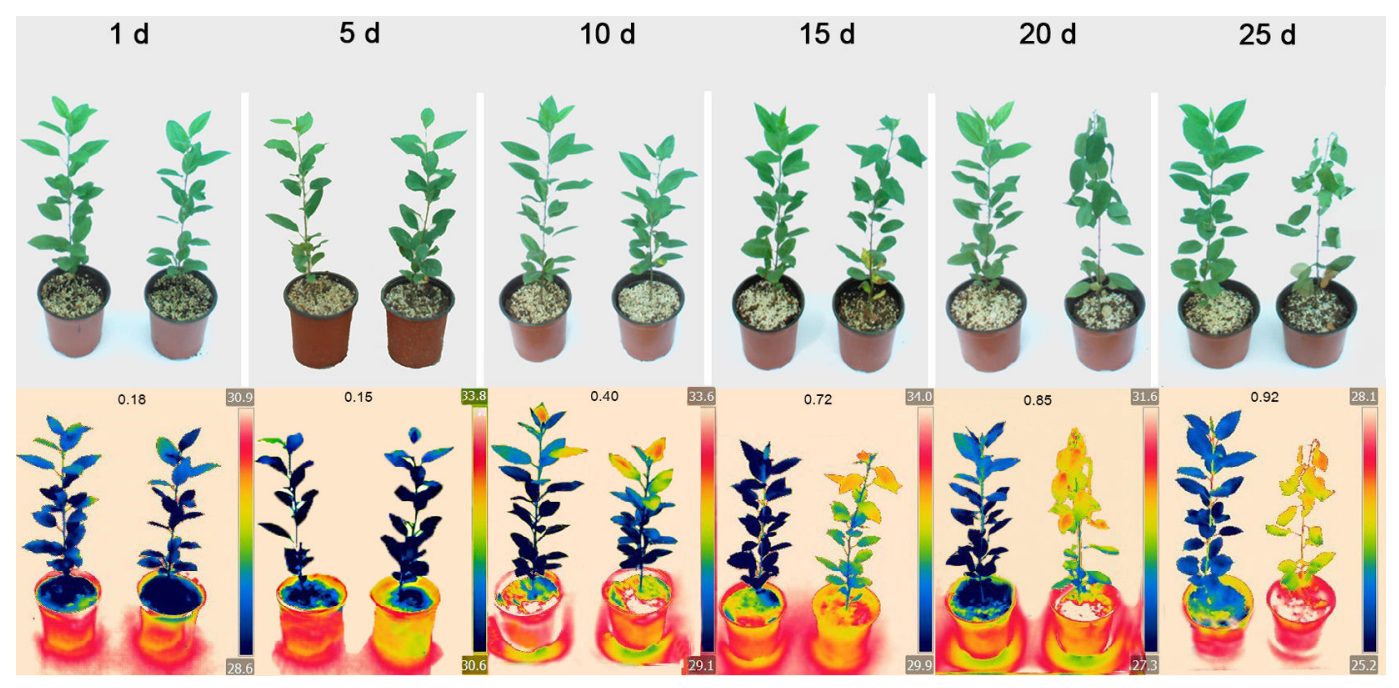

Fig. 4. Detection of leaf temperature of apple plants under different drought durations via infrared thermal imaging. The first and second row show the status of the plants under natural light and infrared light, respectively. The plants shown on the left- and right-hand side of each picture are the control and drought treatment plants, respectively. The data on the infrared image indicate the values of crop water stress index.

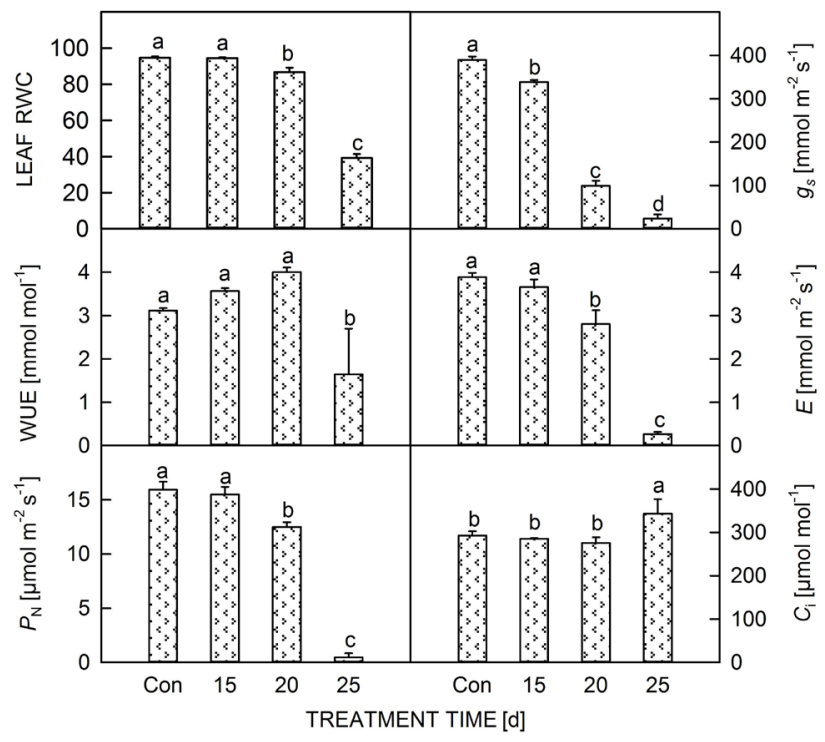

Fig. 5. Changes in the leaf water content, water-use efficiency, and gas-exchange parameters of apple plants after rehydration. $P_{\mathrm{N}}-$ net photosynthetic rate; $g_{\mathrm{s}}-$ stomatal conductance; $C_{\mathrm{i}}$ - intercellular $\mathrm{CO}_{2}$ concentration; $E$ - transpiration rate; WUE - water-use efficiency; Con - control group. Values are means $\pm \mathrm{SD}, n=6$. Different lowercase letters indicate significant differences at $P<0.05$.

those of the control plants. Drought for $15 \mathrm{~d}$ and $20 \mathrm{~d}$ corresponded to stress level 3 and level 4, respectively. In this experiment, the plants completely recovered with rehydration after $15 \mathrm{~d}$ of drought, while old leaves died after $20 \mathrm{~d}$ of drought. After $25 \mathrm{~d}$ of drought, the stress grade reached level 6 ; the plants in this treatment group were all virtually dried up, and all life indexes tended to fall to zero.

\section{Discussion}

Drought not only hinders the growth and metabolism of plants at various stages but also affects the quality and yield of crops (Farooq et al. 2009, Shao et al. 2009, Basu et al. 2016). Most apple plantations reside in arid and semiarid areas, where they are increasingly suffering from the damage caused by drought (Du et al. 2017). In China, with the reduction in arable land and implementation of returning forests to fields in recent years, there is a need for orchards to be relocated to land not suitable for food production, such as mountains, which makes irrigation more difficult. Therefore, research on the effects of drought stress on apple plants will be of great significance to the development of the fruit industry. To our knowledge, this study is the first to combine gas exchange, chlorophyll fluorescence, and infrared thermal imaging technology to describe the effects of drought on the growth of M.9-T337 seedlings in detail.

Leaves are the main organs of plants for photosynthesis and transpiration (Hao et al. 2015, Shao et al. 2016). SWC can affect leaf water content directly, and leaf water content can reflect a plant's water status. Drought stress can lead to a potential or direct decrease in a leaf water content, which can be used as an indicator of whether the plant requires irrigation (Améglio et al. 1999, Cohen et al. 2005). In this study, the water content in the soil decreased significantly earlier than that in the leaves, which indicates that the roots were the first to be affected by soil water shortage, and that soil water shortage gradually reached the leaves a few days later (Fig. 1B,C). When drought stress continued to the $20^{\text {th }}$ day, some leaf edges were scorched and the RWC reduced to $55.5 \%$ (Fig. 1). Under moderate drought stress, photosynthates are preferentially distributed to roots, which promotes root growth and enhances root activity; however, severe drought can 
Table 1. Phenotypic and physiological characteristics of apple plants under different drought grades.

\begin{tabular}{|c|c|c|c|c|}
\hline $\begin{array}{l}\text { Drought } \\
\text { grade }\end{array}$ & Phenotypic and physiological characteristics & $\begin{array}{l}\text { Relative soil } \\
\text { water content }[\%]\end{array}$ & $\begin{array}{l}\text { Relative leaf } \\
\text { water content }[\%]\end{array}$ & $\begin{array}{l}\text { Crop water- } \\
\text { stress index }\end{array}$ \\
\hline 1 & $\begin{array}{l}\text { No significant change in phenotype, but gas-exchange parameters, } \\
\text { leaf temperature, and chlorophyll fluorescence parameters change } \\
\text { significantly }\end{array}$ & $55-65$ & $80-85$ & $0.40-0.50$ \\
\hline 2 & Growth retardation and the color of green leaves deepens & $40-55$ & $75-80$ & $0.50-0.65$ \\
\hline 3 & $\begin{array}{l}\text { Upper leaves droop and wilt (3-6 leaves), the edge of a few old leaves } \\
\text { becomes dry }\end{array}$ & $25-40$ & $65-75$ & $0.65-0.75$ \\
\hline 4 & $\begin{array}{l}\text { The new leaves wilt severely, the upper and middle leaves are drooping } \\
\text { ( } 8-12 \text { leaves), and the old leaves begin to dry }\end{array}$ & $15-25$ & $60-65$ & $0.75-0.85$ \\
\hline 5 & $\begin{array}{l}\text { Except for a few leaves in the middle, the other leaves are curled and } \\
\text { lose water }\end{array}$ & $10-15$ & $45-55$ & $0.85-0.90$ \\
\hline 6 & $\begin{array}{l}\text { The whole plant becomes dry, all vital signs (including photosynthesis } \\
\text { and chlorophyll fluorescence) tend to stop }\end{array}$ & $<10$ & $<30$ & $0.90-1.00$ \\
\hline
\end{tabular}

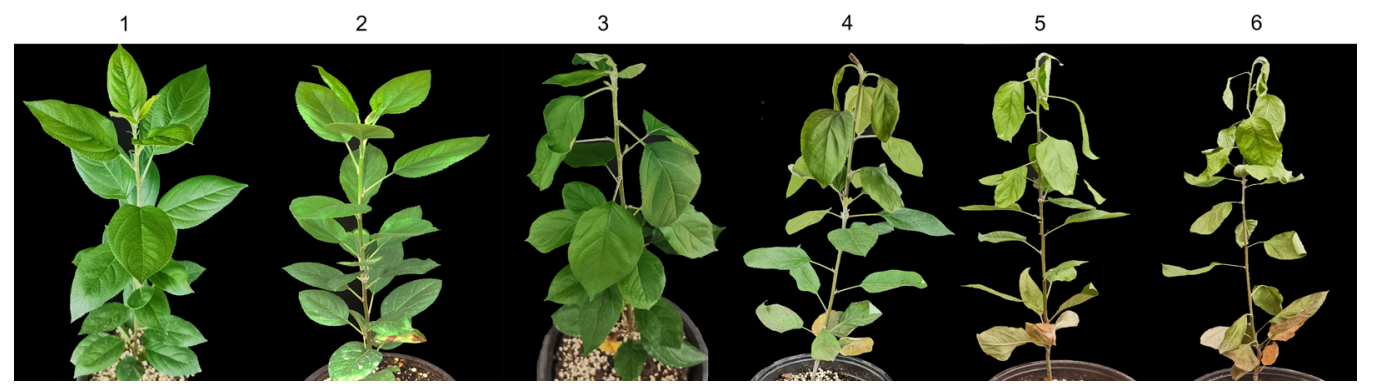

Fig. 6. Plant status under different drought stress grades.

damage root structure and the drought response is partly mediated by the plant hormone abscisic acid (Xiong et al. 2006, Zhang et al. 2006). In this study, as drought damage increased, the brownish color of the roots gradually deepened and the number of fibrous roots gradually decreased (Fig. 1S, Table 1S); thus, the activity of the roots decreased and gradually lost the ability to absorb mineral elements and water. Root growth slows under continuous moderate drought stress and severe drought stress, which is a self-defense mechanism for plants to cope with water deficit (Maxwell and Johnson 2000).

Gas-exchange parameters are effective indexes that reflect the photosynthesis capacity of plants (Baker 2008, Kumagai et al. 2015). Some studies have indicated that the decrease in photosynthesis capacity is usually caused by stomatal limitation under mild to moderate drought conditions when both $g_{\mathrm{s}}$ and $C_{\mathrm{i}}$ decline whereas nonstomatal limitation is the main reason for the decrease in photosynthesis when $C_{\mathrm{i}}$ increases and $g_{\mathrm{s}}$ reaches a minimum inflection point (Pérez-López et al. 2012, Zhou et al. 2013). In this study, the gas-exchange parameters $P_{\mathrm{N}}, g_{\mathrm{s}}$, and $E$ decreased as drought treatment duration prolonged (Fig. $2 A-C$ ). $C_{\mathrm{i}}$ also showed a downward trend in the first $20 \mathrm{~d}$, indicating that before $20 \mathrm{~d}$ of drought stress, a stomatal limiting factor affected photosynthesis. The plant gradually reached a severe drought level after $20 \mathrm{~d}$; when drought lasted for $20 \mathrm{~d}, C_{\mathrm{i}}$ began increasing (Fig. 2C), $g_{\mathrm{s}}$ decreased slowly to a certain extent (Fig. $2 B$ ), and WUE began showing a downward trend (Fig. $2 E$ ). Therefore, the nonstomatal limiting factors become the main factors that affected photosynthesis as most metabolic functions of the leaves began declining; this finding is consistent with that of other studies (Miyashita et al. 2005, Liao et al. 2018).

Chlorophyll fluorescence parameters are tools to quantify the water status of plants during drought stress as they can reflect the effects of drought stress on photosynthesis quickly, accurately, and harmlessly (Longenberger et al. 2009). For most higher plants, the fluctuation range of $\mathrm{F}_{\mathrm{v}} / \mathrm{F}_{\mathrm{m}}$ is very low under nonstress conditions. Even under mild stress, the variation of $\mathrm{F}_{\mathrm{v}} / \mathrm{F}_{\mathrm{m}}$ is not significant but decreases significantly under moderate or high-stress conditions (Pettigrew 2004, Chen et al. 2017). In this study, $\mathrm{F}_{\mathrm{v}} / \mathrm{F}_{\mathrm{m}}$ decreased significantly on the $15^{\text {th }}$ day (Fig. $3 B$ ), indicating that the stress had already reached a moderate level, the active center of PSII showed signs of damage, and photosynthetic electron transfer was inhibited. $Y_{(I I)}$ and $\mathrm{q}_{\mathrm{P}}$ decreased gradually with the duration of drought treatment and NPQ initially increased with the aggravation of drought, indicating that photosynthetic electron transport was blocked, the photosynthetic rate decreased, and light energy captured by the leaves was excessive. However, the redundancy excitation energy could still be eliminated through heat dissipation (Fig. $3 B$ ), which is a protective mechanism of plants (Maxwell and Johnson 2000). Thereafter, NPQ decreased significantly from about $20 \mathrm{~d}$ of drought treatment, which indicated that drought stress caused serious damage to the PSII photoreaction center. A similar conclusion was reported by Woo et al. (2008). 
Infrared thermography has been used to detect drought stress in other plant species (Siddique et al. 2000, WiriyaAlongko et al. 2013, Zia et al. 2013), diseases, and injuries in apple (Baranowski et al. 2008, 2009); however, this study is the first to use infrared thermography to detect apple drought stress. In plants, as the stomata open and the transpiration rate increases, a cooling effect on the leaf surface is produced (evaporative cooling); hence, the plant canopy cools. On contrary, owing to the onset of stress, leaves suffer partial or complete stomatal closure resulting in increased canopy temperatures owing to reduced transpiration rates. Thus, the changes in canopy temperature provide a valuable proxy of $g_{\mathrm{s}}$ and transpiration, which itself is a key indicator of different stress responses (Nilsson 1995, Kashiwagi et al. 2008, Biju et al. 2018). In this study, the temperature difference appeared in a few upper leaves on the $10^{\text {th }}$ day, but there was no difference in the lower leaves (Fig. 4), indicating that the plant still had a certain recovery ability although the upper leaves could not reduce the temperature through transpiration. However, it showed significant differences in leaf temperature at $15 \mathrm{~d}$ of drought stress compared with control plants and revealed the CWSI value of 0.72 (Fig. 4). Other indexes (leaf RWC, gas-exchange parameters, and chlorophyll fluorescence) also changed significantly at this time (Figs. 1, 2, 3), which indicated that plants were suffering from drought stress. Cohen et al. (2005) revealed that the relationship between CWSI and leaf water potential is more stable and has slightly higher correlation coefficients than that between canopy temperature and leaf water potential. Additionally, Wiriya-Alongko et al. (2013) determined the CWSI based on thermal imaging, which accurately detected the degree of drought in the longan tree. In this study, we established a drought stressgrade standard according to the comprehensive parameters of the plants (Table 1).

In addition to the above experiments, we conducted rehydration treatment experiments to test the survival ability of the M.9-T337 plants. After $15 \mathrm{~d}$ of drought, all indexes of leaves returned to normal, including the gasexchange parameters (Fig. 5), leaf temperature (Fig. 2S), and chlorophyll fluorescence parameters (Fig. 3S), which indicated that short-term drought stress was mainly caused by stomatal limitation. The results showed that M.9-T337 had a certain ability to adapt to drought stress. However, continuous moderate drought stress had a significant inhibitory effect on plant physiological processes and caused serious damage to the leaves of M.9-T337. The water rehydration experiment also showed that the $20^{\text {th }}$ day was a critical time point for drought stress; the apple seedlings would die if not watered. At this time, the plants were between drought stress grades 4 and 5; the CWSI and RWC of the leaf and soil were $0.72,60.5 \%$, and $17.84 \%$, respectively. Further, approximately $15 \mathrm{~d}$ of the drought was determined to be the best time for irrigation; the RWC of the soil and leaves was 30.0 and $72.9 \%$, respectively, and the CWSI value was 0.72 .

In summary, this study described in detail the changes in plant state that took place across the entire drought stress process. It also produced a drought stress-grade standard that makes clear that grade 3 is the optimal irrigation period, and found various critical indexes of irreversible damage caused by drought stress that occurred on the $20^{\text {th }}$ day of drought treatment. We hope that our research will provide a theoretical basis for water management and the breeding of drought-resistant apple plants. However, we only studied the physiological response of apple plants to drought. Comprehensive research on plant phenotype, physiology, and the drought resistance molecular mechanism will be the direction of future related research. This will provide a theoretical reference with which to explore the molecular mechanism of the plant drought response, molecular genetic breeding, and agricultural sustainable development.

\section{References}

Améglio T., Archer P., Cohen M. et al:: Significance and limits in the use of predawn leaf water potential for tree irrigation. Plant Soil 207: 155-167, 1999.

Anjum S.A., Xie X.-Y., Wang L.-C. et al.: Morphological, physiological and biochemical responses of plants to drought stress. - Afr. J. Agr. Res. 6: 2026-2032, 2011.

Baker J.T., Gitz D., Payton P. et al.: Using leaf gas exchange to quantify drought in cotton irrigated based on canopy temperature measurements. - Agron. J. 99: 637-644, 2007.

Baker N.R.: Chlorophyll fluorescence: a probe of photosynthesis in vivo. - Annu. Rev. Plant Biol. 59: 89-113, 2008.

Baranowski P., Lipecki J., Mazurek W., Walczak R.T.: Detection of watercore in 'Gloster' apples using thermography. Postharvest Biol. Tec. 47: 358-366, 2008.

Baranowski P., Mazurek W.: Detection of physiological disorders and mechanical defects in apples using thermography. Int. Agrophys. 23: 9-17, 2009.

Baranowski P., Mazurek W., Witkowska-WalczakB., SławińskiC.: Detection of early apple bruises using pulsed-phase thermography. - Postharvest Biol. Tec. 53: 91-100, 2009.

Bartels D., Sunkar R.: Drought and salt tolerance in plants. Crit. Rev. Plant Sci. 24: 23-58, 2005.

Basu S., Ramegowda V., Kumar A., Pereira A.: Plant adaptation to drought stress. - F1000Res. 5: 1554, 2016.

Biju S., Fuentes S., Gupta D.: The use of infrared thermal imaging as a non-destructive screening tool for identifying drought-tolerant lentil genotypes. - Plant Physiol. Bioch. 127: $11-24,2018$.

Bilger W., Björkman O.: Role of the xanthophyll cycle in photoprotection elucidated by measurements of light-induced absorbance changes, fluorescence and photosynthesis in leaves of Hedera canariensis. - Photosynth. Res. 25: $173-$ 185, 1990.

Centritto M., Brilli F., Fodale R., Loreto F.: Different sensitivity of isoprene emission, respiration and photosynthesis to high growth temperature coupled with drought stress in black poplar (Populus nigra) saplings. - Tree Physiol. 31: 275-286, 2011.

Chen Y., Wang Z., Shen Z. et al.: Effects of oxytetracycline on growth and chlorophyll fluorescence in rape (Brassica campestris L.). - Pol. J. Environ. Stud. 26: 995-1001, 2017.

Cohen Y., Alchanatis V., Meron M. et al.: Estimation of leaf water potential by thermal imagery and spatial analysis. J. Exp. Bot. 56: 1843-1852, 2005.

Du S.Q., Kang S.Z., Li F.S., Du T.S.: Water use efficiency is improved by alternate partial root-zone irrigation of apple in arid northwest China. - Agr. Water Manage. 179: 184-192, 
2017.

Earl H.J.: Stomatal and non-stomatal restrictions to carbon assimilation in soybean (Glycine max) lines differing in water use efficiency. - Environ. Exp. Bot. 48: 237-246, 2002.

Escalona J.M., Flexas J., Medrano H.: Stomatal and non-stomatal limitations of photosynthesis under water stress in field-grown grapevines. - Funct. Plant Biol. 26: 421-433, 1999.

Farage P.K., Blowers D., Long S.P., Baker N.R.: Low growth temperatures modify the efficiency of light use by photosystem II for $\mathrm{CO}_{2}$ assimilation in leaves of two chilling-tolerant $\mathrm{C}_{4}$ species, Cyperus longus L. and Miscanthus $\times$ giganteus. Plant Cell Environ. 29: 720-728, 2006.

Farooq M., Wahid A., Kobayashi N. et al.: Plant drought stress: effects, mechanisms and management. - Agron. Sustain. Dev. 29: 185-212, 2009.

Figueroa F.L., Conde-Álvarez R., Gómez I.: Relations between electron transport rates determined by pulse amplitude modulated chlorophyll fluorescence and oxygen evolution in macroalgae under different light conditions. - Photosynth. Res. 75: 259-275, 2003.

Gao D., Guo J., Wei Z. et al.: Evaluation of productivity and light quality in two high density dwarf rootstock apple orchards in central China. - Agr. Sci. Technol. 13: 1848-1853, 2012.

Genty B., Briantais J.-M., Baker N.R.: The relationship between the quantum yield of photosynthetic electron transport and quenching of chlorophyll fluorescence. - BBA-Gen. Subjects 990: 87-92, 1989.

Hao P., Zhu J., Gu A. et al:: An integrative proteome analysis of different seedling organs in tolerant and sensitive wheat cultivars under drought stress and recovery. - Proteomics 15: 1544-1563, 2015.

Henriques F.S.: Leaf chlorophyll fluorescence: background and fundamentals for plant biologists. - Bot. Rev. 75: 249-270, 2009.

Hogewoning S.W., Harbinson J.: Insights on the development, kinetics, and variation of photoinhibition using chlorophyll fluorescence imaging of a chilled, variegated leaf. - J. Exp. Bot. 58: 453-463, 2007.

Höhnle M.K., Weber G.: Efficient adventitious shoot formation of leaf segments of in vitro propagated shoots of the apple rootstock M.9/T337. - Eur. J. Hortic. Sci. 75: 128-131, 2010.

Idso S.B., Jackson R.D., Pinter Jr P.J. et al.: Normalizing the stress-degree-day parameter for environmental variability. Agr. Meteorol. 24: 45-55, 1981.

Jaleel C.A., Manivannan P., Wahid A. et al.: Drought stress in plants: a review on morphological characteristics and pigments composition. - Int. J. Agric. Biol. 11: 100-105, 2009.

Jensen P.J., Halbrendt N., Fazio G. et al.: Rootstock-regulated gene expression patterns associated with fire blight resistance in apple.-BMC Genomics 13: 9, 2012.

Jiang H.X., Chen L.S., Zheng J.G. et al:: Aluminum-induced effects on photosystem II photochemistry in citrus leaves assessed by the chlorophyll $a$ fluorescence transient. - Tree Physiol. 28: 1863-1871, 2008.

Jones H.G.: Application of thermal imaging and infrared sensing in plant physiology and ecophysiology. - Adv. Bot. Res. 41: 107-163, 2004

Kashiwagi J., Krishnamurthy L., Upadhyaya H.D., Gaur P.M.: Rapid screening technique for canopy temperature status and its relevance to drought tolerance improvement in chickpea. J. SAT Agric. Res. 6: 105, 2008.

Khanal S., Fulton J., Shearer S.: An overview of current and potential applications of thermal remote sensing in precision agriculture. - Comput. Electron. Agr. 139: 22-32, 2017.

Kumagai E., Araki A., Kubota F.: Correlation of chlorophyll meter readings with gas exchange and chlorophyll fluorescence in flag leaves of rice (Oryza sativa L.) plants. - Plant Prod. Sci. 12: 50-53, 2015.

Leinonen I., Grant O.M., Tagliavia C.P.P. et al.: Estimating stomatal conductance with thermal imagery. - Plant Cell Environ. 29: 1508-1518, 2006.

Liao T., Wang Y., Xu C.P. et al.: Adaptive photosynthetic and physiological responses to drought and rewatering in triploid Populus populations. - Photosynthetica 56: 578-590, 2018.

Lima R.S.N., García-Tejero I., Lopes T.S. et al.: Linking thermal imaging to physiological indicators in Carica papaya L. under different watering regimes. - Agr. Water Manage. 164: 148-157, 2016.

Liu Y., Li S., Chen F. et al.: Soil water dynamics and water use efficiency in spring maize (Zea mays L.) fields subjected to different water management practices on the Loess Plateau, China. - Agr. Water Manage. 97: 769-775, 2010.

Liu Y., Subhash C., Yan J. et al.: Maize leaf temperature responses to drought: Thermal imaging and quantitative trait loci (QTL) mapping. - Environ. Exp. Bot. 71: 158-165, 2011.

Longenberger P.S., Smith C.W., Duke S.E., McMichael B.L.: Evaluation of chlorophyll fluorescence as a tool for the identification of drought tolerance in upland cotton. Euphytica 166: 25, 2009.

Maxwell K., Johnson G.N.: Chlorophyll fluorescence a practical guide. - J. Exp. Bot. 51: 659-668, 2000.

Miyashita K., Tanakamaru S., Maitani T., Kimura K.: Recovery responses of photosynthesis, transpiration, and stomatal conductance in kidney bean following drought stress. Environ. Exp. Bot. 53: 205-214, 2005.

Nilsson H.-E.: Remote sensing and image analysis in plant pathology. - Annu. Rev. Phytopathol. 15: 489-527, 1995.

Oxborough K., Baker N.R.: Resolving chlorophyll $a$ fluorescence images of photosynthetic efficiency into photochemical and non-photochemical components - calculation of $\mathrm{q}_{\mathrm{p}}$ and $\mathrm{F}_{\mathrm{v}}{ }^{\prime} / \mathrm{F}_{\mathrm{m}}{ }^{\prime}$ without measuring $\mathrm{F}_{0}^{\prime}$. - Photosynth. Res. 54: 135-142, 1997.

Pérez-López U., Robredo A., Lacuesta M. et al.: Elevated $\mathrm{CO}_{2}$ reduces stomatal and metabolic limitations on photosynthesis. - Photosynth. Res. 111: 269-283, 2012.

Pettigrew W.T.: Physiological consequences of moisture deficit stress in cotton. - Crop Sci. 44: 1265-1272, 2004.

Ring E.F.J., Ammer K.: Infrared thermal imaging in medicine. Physiol. Meas. 33: R33, 2012.

Schreiber U., Quayle P., Schmidt S. et al.: Methodology and evaluation of a highly sensitive algae toxicity test based on multiwell chlorophyll fluorescence imaging. - Biosens. Bioelectron. 22 : 2554-2563, 2007.

Schreiber U., Schliwa U., Bilger W.: Continuous recording of photochemical and non-photochemical chlorophyll fluorescence quenching with a new type of modulation fluorometer. - Photosynth. Res. 10: 51-62, 1986.

Shao H.-B., Chu L.-Y., Jaleel C.A. et al.: Understanding water deficit stress-induced changes in the basic metabolism of higher plants - biotechnologically and sustainably improving agriculture and the ecoenvironment in arid regions of the globe. - Crit. Rev. Biotechnol. 29: 131-151, 2009.

Shao H.F., Chen Z., Xu J.: [Physiological responses of two tobacco cultivar leaves to different drought stresses during seedling stage.] - Plant Physiol. J. 12: 1861-1871, 2016. [In Chinese]

Siddique M.R.B., Hamid A., Islam M.S.: Drought stress effects on water relations of wheat. - Bot. Bull. Acad. Sin. 41: 35-39, 2000.

Silva M.D.A., Jifon J.L., da Silva J.A.G. et al.: Use of physiological parameters as fast tools to screen for drought tolerance in sugarcane. - Braz. J. Plant Physiol. 19: 193-201, 2007. 
Srivastava K.K., Kumar D., Singh S.R., Sharma O.C.: Effect of cultivars on tree growth, yield and quality attributes of apple on espalier architecture under high density planting system. J. Hortic. Sci. 14: 20-25, 2019.

Vadivambal R., Jayas D.S.: Applications of thermal imaging in agriculture and food industry - a review. - Food Bioproc. Tech. 4: 186-199, 2011.

van Rensburg L., Krüger G.H.J.: Comparative analysis of differential drought stress-induced suppression of and recovery in carbon dioxide fixation: stomatal and non-stomatal limitation in Nicotiana tabacum L. - J. Plant Physiol. 142: 296-306, 1993.

Varith J., Hyde G.M., Baritelle A.L. et al.: Non-contact bruise detection in apples by thermal imaging. - Innov. Food Sci. Emerg. Technol. 4: 211-218, 2003.

Wang M., Xiong Y., Ling N. et al.: Detection of the dynamic response of cucumber leaves to fusaric acid using thermal imaging. - Plant Physiol. Bioch. 66: 68-76, 2013.

Weber M.S.: Optimizing the tree density in apple orchards on dwarf rootstocks. - Acta Hortic. 557: 229-234, 2001.

Wiriya-Alongko W., Spreer W., Ongprasert S. et al.: Detecting drought stress in longan tree using thermal imaging. - Maejo. Int. J. Sci. Technol. 7: 166-180, 2013.
Woo N.S., Badger M.R., Pogson B.J.: A rapid, non-invasive procedure for quantitative assessment of drought survival using chlorophyll fluorescence. - Plant Methods 4: 27, 2008.

Xiong L., Wang R.G., Mao G., Koczan J.M.: Identification of drought tolerance determinants by genetic analysis of root response to drought stress and abscisic acid. - Plant Physiol. 142: 1065-1074, 2006.

Zai X.M., Zhu S.N., Qin P. et al.: Effect of Glomus mosseae on chlorophyll content, chlorophyll fluorescence parameters, and chloroplast ultrastructure of beach plum (Prunus maritima) under $\mathrm{NaCl}$ stress. - Photosynthetica 50: 323-328, 2012.

Zhang J.H., Jia W.S., Yang J.C., Ismail A.M.: Role of ABA in integrating plant responses to drought and salt stresses. Field Crop. Res. 97: 111-119, 2006.

Zhou S., Duursma R.A., Medlyn B.E. et al.: How should we model plant responses to drought? An analysis of stomatal and non-stomatal responses to water stress. - Agr. Forest Meteorol. 182-183: 204-214, 2013.

Zia S., Romano G., Spreer W. et al.: Infrared thermal imaging as a rapid tool for identifying water-stress tolerant maize genotypes of different phenology. - J. Agron. Crop Sci. 199: 75-84, 2013.

(C) The authors. This is an open access article distributed under the terms of the Creative Commons BY-NC-ND Licence. 